
\title{
25 Research Square \\ Effects of ambient temperature and air pollutants on bacillary dysentery from 2014 to 2017 in Lanzhou, China
}

\section{Xiaoli Han}

Lanzhou University

\section{Wei Zhang}

Lanzhou Center for Disease Control and Provention

\section{Xudong Cui}

Lanzhou University

\section{Hanping Ma}

Lanzhou Center for Disease Control and Prevention

\section{Yanchen Liu}

Lanzhou University

\section{Xiaoyu Zhang}

Lanzhou Center for DIsease Control and Prevention

\section{Xiangkai Zhao}

Lanzhou University

\section{Sheng Li}

Lanzhou Center for Disease Control and Prevention

Xiaowei Ren ( $\nabla$ renxw@lzu.edu.cn )

Lanzhou University

\section{Research article}

Keywords: Bacillary dysentery, Temperature, Air pollutants, DLNM model, Lanzhou city

Posted Date: April 17th, 2020

DOI: https://doi.org/10.21203/rs.2.13650/v2

License: (c) (1) This work is licensed under a Creative Commons Attribution 4.0 International License. Read Full License 


\section{Abstract}

Background : Previous studies have always focused on the impact of various meteorological factors on bacillary dysentery (BD). However, only few studies have investigated the effects of climate and air pollutants on BD incidence simultaneously. This study aimed to investigate the effects of temperature and air pollutants on BD in Lanzhou.

Methods: Daily data of BD cases and environmental factors from 2014 to 2017 were collected. A generalized additive model (GAM) was conducted to explore the relationship between environmental factors and BD. Then a distributed lag non-linear model (DLNM) was developed to assess the lag and cumulative effect. Furthermore, this study explored the variability across gender and age groups.

Results: A total of 7102 cases of BD were notified over the study period. High temperature can significantly increase the risk of BD during the whole lag period, temperature has different exposure effects on different genders and age groups. With $9^{\circ} \mathrm{C}$ as the reference value, each $1{ }^{\circ} \mathrm{C}$ rise in temperature result in a $4.8 \%(R R=1.048,95 \% \mathrm{Cl}: 0.996,1.103)$ increase in the number of cases $\mathrm{BD}$ at lag 0 day. With $50 \mu \mathrm{g} / \mathrm{m} 3$ as the reference value, each $5 \mu \mathrm{g} / \mathrm{m} 3$ rise in PM2.5 caused a $11.3 \%(R R=1.113$, $95 \% \mathrm{Cl}: 1.066,1.162)$ increase in the number of BD cases at lag 0 . Low concentration of PM10 in the lag of 10-14 days can significantly increase the risk of BD, while high concentration PM10 in the lag of 6-14 days can significantly increase the risk of BD.

Conclusions: Temperature, PM2.5 and PM10 are closely related to the incidence of bacillary dysentery. Our findings suggest adaptation plans that target vulnerable populations in susceptible communities should be developed to reduce health risks.

\section{Background}

Bacillary dysentery, also known as shigellosis, is an acute intestinal infectious disease caused by diarrhea bacillus(Zhou yanli, 2009). The infection is spread from person to person via fecal-oral route, contaminated water and food, flies and direct contacts to a patient or carrier(Liu et al., 2019). Epidemics are frequent in overcrowded populations with poor sanitation and most cases occur in summer and autumn. While most cases of bacillary dysentery are mild and do not require drastic treatment, excessive dehydration can be fatal in a severe attack if treatment is unsuccessful(Zhang et al., 2007). According to the National Report of Notifiable Disease from the Center for Disease Control and Prevention in China, there were approximately 109,368 notified cases of bacillary dysentery in 2017 , with an incidence rate of 7.92 per 100,000 , which is ranked to be the fifth highest number of statutory infectious diseases in category B. Shigella infections remain an important public health problem in China, especially among children and old people(von Seidlein et al., 2006; Xuan-yi Wang et al., 2006). Many studies also showed that bacillary dysentery was one of the major infectious diseases affecting the health and quality of life of residents in China(SUN et al., 2008; Li et al., 2018; Liu et al., 2016; Ma et al., 2015). 
In recent years, more and more scholars have applied various kinds of statistic methods to interpret the association between meteorological factors and the incidence of bacillary dysentery and it showed that meteorological factors are closely related to the incidence of bacillary dysentery. Chen analyzed the epidemic characteristics of bacillary dysentery and meteorological factors in Henan province in 2010 by using single factor correlation analysis and multivariate linear regression, and found that the incidence of bacillary dysentery was related to precipitation and temperature.(CHEN Wei, 2012). The principal component analysis and time series analysis were used to analyze the meteorological factors and the number of bacillary dysentery in Chengguan district, Lanzhou city from 2005 to 2010, suggesting that the incidence of bacillary dysentery in this area was related to high temperature(QIANG Li, 2013). Zhang used $\mathrm{BP}$ artificial neural network model to analyze the relationship between bacillary dysentery and meteorological factors in Beijing area, and found that the risk of bacillary dysentery was not only related to the relative humidity and wind speed of the current year, but also related to the previous one to three years(Juan, 2015). Gao used multivariate stationary time series ARIMAX model to quantitatively evaluate the correlation between the meteorological elements and the incidence of bacillary dysentery in Changsha city, and found that the meteorological factors having great influence on the incidence of bacillary dysentery were temperature, air pressure and precipitation (Gao et al., 2014). The relationship between meteorological factors and the incidence of bacillary dysentery in Jinan were discussed by using generalized additive model, and it was concluded that temperature was an important meteorological factor affecting the incidence of bacillary dysentery(Liu et al., 2019). The relationship between bacillary dysentery and meteorological factors in Binyang, Guangxi, was discussed by using principal component analysis and classification regression tree, and found that temperature, rainfall and humidity played an important role in the propagation of bacillary dysentery (Liu et al., 2017).

Through consulting the literature, it was found that most of the studies only focused on the relationship between meteorological factors such as temperature and relative humidity and bacillary dysentery, and there are few studies on the relationship between air pollutants and gastrointestinal diseases such as bacillary dysentery. However, there are studies that have identified a new biological mechanism to explain adverse health effects from air pollution: epigenetics (Bollati and Baccarelli, 2010; Hou et al., 2012). A study suggested that DNA methylation is a mechanism that cells use to control gene expression in a switch-like manner(Zhang et al., 2009). Complement component C3,an important factor in the human defense system, turned out to be a sensitive indicator of immunological reactions to common air pollutants(Renate Stiller- Winkler and Gahiele Leng, 1996). On one hand, high temperature can directly affect the body's cardiovascular system and respiratory system, leading to a reduction in the body's immune power in the epidemic and makes the exposed population vulnerable to a variety of infectious pathogens(Bai et al., 2014; Kim et al., 2014), on the other hand, air pollution may amplify people's vulnerability to the adverse effects of temperature(Gordon, 2003) and could act as an effective modifier in the short-term effects of air temperature on disease (Breitner et al., 2014; Ren et al., 2006). Therefore, it is of great significance to explore the effects of air pollutants on incidence of bacillary dysentery.

Although there are many studies on the relationship between the incidence of dysentery and environmental factors, few studies have been studied in semi-arid areas. Lanzhou is located in the 
intersection of the three highlands like the Tibet Plateau, the Loess Plateau and the Inner Mongolian Plateau, and belongs to the semi-arid region and temperate continental climate. In addition, the elevation of Lanzhou is more than 1,500 meters.So it is of great significance to explore the relationship between the incidence of dysentery and environmental factors in semi-arid areas.

Many studies have used principal component analysis, single-factor correlation analysis and multivariate linear model to analyze the relationship between bacillary dysentery and meteorological factors, but these studies did not consider the nonlinear relationship between meteorological factors and the incidence of bacillary dysentery. In addition, traditional single models (such as generalized linear models, generalized additive models, sliding averaging methods etc) only take into account the effects of a particular time period, and simply introduce the exposure level for several consecutive days in the model, regardless of the characteristics of hysteresis distribution, which is bound to produce a high col-linearity, and not to accurately reveal the relationship between meteorological factors and disease(YANG Jun, 2012).

The study aims to quantify the relationship between environmental factors and bacillary dysentery in Lanzhou, with consideration of lagged and cumulative effects. It will contribute to a better understanding of the health impacts of environmental factors and provide evidence to support decision-making for prevention and control of BD.

\section{Methods}

\section{Data collection}

Notified data of daily number of BD cases between January 2014 and December 2017 in Lanzhou were obtained from Center for Disease Control and Prevention of Lanzhou city. In this study, all bacillary dysentery cases were defined based on the diagnostic criteria and principles of management for dysentery (GB 16002-1995), issued by the Ministry of Health of the People's Republic of China.

Daily meteorological data for Lanzhou were extracted from the publicly accessible China National Weather Data Sharing System. The meteorological variables included daily mean temperature, relative humidity, air pressure, wind speed and sunshine duration. Data of air pollutants was obtained from the local environmental protection station and included PM2.5, $\mathrm{PM} 10, \mathrm{CO}, \mathrm{NO}_{2}$ and $\mathrm{O}_{3}$. The location of Lanzhou, Gansu, Province in China was showed in Figure 1.

\section{Statistical methods}

Firstly, a descriptive analysis was performed to describe the distribution of BD cases and environmental factors during the study period. Then the correlation between the environmental factors and the number of daily incidence of bacillary dysentery in Lanzhou was analyzed by adopting Spearman grade correlation, and the meteorological factors and air pollutants related to the incidence of bacillary 
dysentery were included in the model. A generalized additive model(GAM) was developed to examine the exposure-response relationship between environmental factors and the BD cases, with the consideration of different lag period of environmental factors. As an initial exploratory analysis, the result of GAM was used by the following models. A distributed lag non-linear model (DLNM) was applied to estimate the cumulative and delayed effects of the environmental factors on BD.

The cross-base matrix was established for the daily cases of bacillary dysentery and environmental factors, respectively. The number of daily bacillary dysentery as the dependent variable was fitted by quasi-Poisson connection function. Based on the control of seasonal, long-term trends and weekly effects, distributed lag non-linear model (DLNM) was used to fit the correlation between environmental factors and the cases of bacillary dysentery. The influence of daily temperature, daily PM2.5 and PM10 on the incidence of bacterial dysentery was analyzed, while the confound effects of relative humidity, sunshine time, wind speed, $\mathrm{CO}, \mathrm{NO}_{2}$ and $\mathrm{O}_{3}$ were controlled. Finally, a two-dimensional matrix of temperature, PM2.5, PM10 and lag time was established to study the lag effect of temperature, PM2.5 and PM10 on the BD. The basic model is following.

Where is the expected daily count of BD on day $t, a$ is the intercept. $\beta, \gamma$ and $\lambda$ were the effect estimate of temperature, PM2.5 and PM10. represented the thin plate splines function, which were used to adjust for other environmental factors and long-term and seasonal trends. According to the relevant investigation, we selected 14 days as the maximum lag period(WANG Jin-yu1, 2018). Using the median value of daily temperature, PM2.5 and PM10 as reference values, the relative risk (RR) values of different temperatures, PM2.5 and PM10 and different lag time were calculated. In this study, R3.5.0 software was used for statistical analysis and DLNM program package was used to fit regression model, the test level is 0.05 .

\section{Results}

1. Descriptive analysis of BD and environment factors

During the four-year period from 1 January, 2014 to 31 December, 2017, there were a total of 7,102 BD cases, with an average daily BD cases of 4.84 . The cases of BD among male was approximately 1.17 times as high as that among female. Children under 6 years old were at the highest proportion(38.2\%) of BD. The average daily mean temperature, $\mathrm{PM}_{2.5}$ and $\mathrm{PM}_{10}$ were $7.73^{\circ} \mathrm{C}, 53.44 \mu \mathrm{g} / \mathrm{m}^{3}$ and $124.47 \mu \mathrm{g} / \mathrm{m}^{3}$, respectively(Table 1).

\section{Correlation analysis between BD and environment factors}

The correlation between the incidence of bacillary dysentery and PM2.5, PM10, CO, NO2 and 03 was statistically significant $(p<0.05)$, respectively. The incidence of bacillary dysentery was negatively correlated with PM2.5, PM10, $\mathrm{CO}$ and $\mathrm{NO}_{2}$, while was positively correlated with $\mathrm{O}_{3}$. The correlation 
coefficients between the mean temperature, PM2.5, PM10 and the cases of BD were $0.58,-0.39$ and -0.33 , respectively.

\section{Exploratory analysis of the relationship between temperature and BD}

The maximum temperature, minimum temperature, and mean temperature were respectively used to fit the GAM, in which the model fitted by the mean temperature was generally associated with the lowest generalized cross-validation value(GCV, means that the model fitted by mean temperature had the best predictive ability for incidence), therefore we only reported results for associations with mean temperature.

After adjusting the confounding factor such as air pressure, relative humidity, wind speed $\mathrm{PM}_{2.5}$ and $\mathrm{PM}_{10}$, the effect of mean temperature on bacterial dysentery is shown below. As shown in Figure $2 \mathrm{a}$, the three-dimensional plot shows the entire surface between mean temperature and daily cases of bacillary dysentery at all lag days. The estimated effect of mean temperature was non-linear for daily cases of bacillary dysentery, with higher relative risk at hot temperature. For example, hot temperature $\left(19^{\circ} \mathrm{C}\right)$ and cold temperature $\left(-16^{\circ} \mathrm{C}\right)$ were positively associated with daily cases of bacillary dysentery on the current day. Cold effects (i.e., significant increases in incidence associated with cold temperature) was not apparent after a 6-day lag, with relative risk close to 1 when the temperature below $0^{\circ} \mathrm{C}$. Figure $2 \mathrm{~b}$ shows the estimated effect of mean temperature over 14 days on daily cases of bacillary dysentery. There was $\mathrm{J}$-shaped relationship between mean temperature and daily cases of bacillary dysentery, with a large comfortable temperature range where the relative risk of cases of bacillary dysentery was less than 1 when mean temperature was below $10^{\circ} \mathrm{C}$. In contrast, during all lag period, when mean temperature above $10^{\circ} \mathrm{C}$, the risk of bacterial dysentery increased with increasing temperature.

The single-lag effects of temperature on bacillary dysentery in each subgroup was shown in Table 2, except for people aged 41 years and over, suggesting that temperature effects on BD appeared to be acute and greatest on the day of exposure(lag of 0 days). Significant temperature effect appeared after a 3-day lag for people aged 41 years and over, whereas that occurred within 0-6 days, 0-3 days, 0-11 days and 0-6 days for male, female, people aged 0-6 years and aged 7-40 years, respectively. Association between temperature and BD for people aged 0-6 years lasted longer than other subgroup, the effect value decreased with increasing lag days, and the effect on the day of exposure was the greatest, a $1^{\circ} \mathrm{C}$ increase in mean temperature was associated with a $2.0 \%(\mathrm{RR}=1.02,95 \% \mathrm{Cl}: 1.013,1.028)$ increase in cases of BD. The effect of temperature on BD for people aged 41 years and over occurred within 9-14 days and the effect values were less than 1 .

The cumulative effects of mean temperature on BD stratified by age and sex were illustrated in Figure 3 . This suggested that mean temperature was significantly associated with bacillary dysentery in male and female, and people aged 0-6 years, 7-40 years, but not with bacillary dysentery in people aged 41 years and over. The mean temperature-bacillary dysentery patterns for female and people aged 0-6 years were 
similar, with the relative risk increasing significantly when mean temperature was more than $10^{\circ} \mathrm{C}$. In general, hot effect of lag 0-14 days was greater than cold effect of lag 0-14 days.

\section{Exploratory analysis of the relationship between PM2.5 and BD}

After adjusting the confounding factors such as temperature, air pressure, relative humidity, wind speed and PM10, the effect of PM2.5 on bacterial dysentery is shown below. Figure 4 depicts the effect of PM2.5 on BD. It is illustrated by 3D image and overall effect plot of the relative risk of BD. The 3D plot showed a very strong immediate positive effect of the PM2.5 concentration above around $100 \mu \mathrm{g} / \mathrm{m}^{3}$ at lag 0-2 days, indicating that a high number of BD cases would occurred within the first 0-2 days of any polluted weather crossing the PM2.5 of $100 \mu \mathrm{g} / \mathrm{m}^{3}$. Higher concentration of PM2.5 also seemed to have a moderate effect on BD at around 8-14 days lag period, while lower concentration of PM2.5 seemed to have a moderate positive effect on BD at around 0-6 days lag period.. Figure $4 \mathrm{~b}$ shows the estimated effect of PM2.5 over 14 days on daily cases of bacillary dysentery. There was an inverted S-shaped curve, indicating that PM2.5 was associated with a decrease in BD occurrence with concentration of PM2.5 increasing when it was below $50 \mathrm{ug} / \mathrm{m}^{3}$ and above $150 \mathrm{ug} / \mathrm{m}^{3}$, whereas PM2.5 was associated with a increase in BD occurrence with concentration of PM2.5 increase when it ranged $50 \mathrm{ug} / \mathrm{m}^{3}$ and $150 \mathrm{ug} / \mathrm{m}^{3}$.

Table 3 shows the single-lag effects of PM2.5 on bacillary dysentery in each subgroup. Except for people aged 7-40 years, the effects of temperature on BD appeared to be acute and greatest on the day of exposure(lag of 0 days). However, the lag time of PM2.5 on BD for people aged 0-6 years and 41 years and over, and male was nine days, which differed from that in female (14 days). The effect of PM2.5 for people aged 7-40 years was not statistically significant during the whole lag period. In particular, the effect of PM2.5 on BD for children aged 0-6 years was greater than other subgroup, each $5 \mathrm{ug} / \mathrm{m}^{3}$ increase in PM2.5 corresponded to an increase of $2.1 \%(\mathrm{RR}=1.021,95 \% \mathrm{Cl}: 1.014,1.027)$ in cases of $\mathrm{BD}$.

As shown in Figure 5, the cumulative effects of PM2.5 on different genders and age groups were nonlinear. This suggested that PM2.5 was significantly associated with BD in male and female, and people aged 0-6 years and 41 years and over when it's concentration below $50 \mathrm{ug} / \mathrm{m}^{3}$, but not with BD in people aged 7-40 years. The effects of PM2.5 on BD for male, and people aged 0-6 years were similar, with the relative risk increasing significantly when PM2.5 was above $50 \mathrm{ug} / \mathrm{m}^{3}$, while the relative risk decreasing significant when PM2.5 was below $50 \mathrm{ug} / \mathrm{m}^{3}$. The effects of PM2.5 on BD for female, and people aged 41 years and over were increasing significantly when PM2.5 was between $50 \mathrm{ug} / \mathrm{m}^{3}$ and $150 \mathrm{ug} / \mathrm{m}^{3}$.

5. Exploratory analysis of the relationship between PM10 and BD 
After adjusting the confounding factors such as temperature, air pressure, relative humidity, wind speed and PM2.5, the effect of PM10 on bacterial dysentery is shown below. Figure 6a showed the nonlinear relationship and lag effect between PM10 and BD. When the concentration of PM10 was lower than $110 \mu \mathrm{g} / \mathrm{m}^{3}$, there seemed to have a moderately positive effect on BD at around 10-14 day lag period, which indicated that the lower concentration of PM10 could significantly increase the risk of BD when delayed 10-14 days. On the contrary, when the concentration of PM10 was greater than $110 \mu \mathrm{g} / \mathrm{m}^{3}$, there seemed to have a strong positive effect on BD at lag 10-14 days. There were also some shorter lag periods (0-3 days) but negative effects when the concentration of PM10 was higher than around $110 \mu \mathrm{g} / \mathrm{m}^{3}$. Figure $6 \mathrm{~b}$ shows the estimated effect of PM10 over 14 days on BD. There was U-shaped relationships between PM10 and BD, means the effect of low or high concentration of PM10 was associated with a increase in BD occurrences.

As shown in Table 4, taking $110 \mu \mathrm{g} / \mathrm{m} 3$ as reference value, at lag 14 days, each $10 \mu \mathrm{g} / \mathrm{m}^{3}$ increase in PM10 corresponded to an increase of $0.3 \%(R R=1.003,95 \% \mathrm{Cl}: 1.001,1.006)$ and $0.1 \%(R R=1.001,95 \% \mathrm{Cl}$ : $0.999,1.005$ ) in cases of $\mathrm{BD}$ for male and $\geq 41$ years old people, respectively. At the lag 0 day, the increased risk for people aged $7-40$ years was $0.1 \%$ ( $R R=1.001,95 \% \mathrm{Cl}: 0.996,1.003)$. The risk of $B D$ in women and people aged 0-6 years decreased during the whole lag period, and with the number of lag days increasing, the amount of female decline increases gradually, while the reduction in people aged 0-6 years gradually decreased.

As shown in Figure 6, the cumulative effects of PM10 on different genders and age groups were nonlinear. The effects of PM10 on BD for male and female, and people aged 7-40 years and aged 41 years and over were similar, with the relative risk increasing significantly when PM10 was below $200 \mathrm{ug} / \mathrm{m}^{3}$.

\section{Discussion}

Bacillary dysentery, as a legal infectious disease in China, has been in the top five in the reporting system of statutory infectious diseases in China in recent years, and the incidence of bacillary dysentery varies greatly in different regions. Studies have shown that the incidence rate in Lanzhou city was significantly higher than that in the whole country and other regions (Liu et al., 2016). Therefore, the study on the factors affecting the incidence of bacillary dysentery has important hygienic significance for the prevention and control of diseases, and provides a scientific basis for the relevant institutions to formulate preventive measures.

In this study, we observed non-linear and delayed effects of daily mean temperature on BD cases. The results showed that significant associations between high temperature and $\mathrm{BD}$ (hot effects) appeared at the day of exposure and lasted 14 days, which was similar to the findings of previous studies. For example, the study by Li revealed that the incidence of BD would increase by $1.58 \%$ for each $1^{\circ} \mathrm{C}$ rise in daily mean temperature (Li et al., 2016). A study conducted in Jinan also found that for each $5^{\circ} \mathrm{C}$ increase in daily average temperature, the incidence of BD increased by 61\%(Liu et al., 2019). A possible 
explanation could be that the growth and reproduction of shigella were inhibited under the condition of low temperature (Checkley et al., 2000). A study exploring the attributable fraction (AF) under varying temperature found that temperature was positively associated with $\mathrm{BD}$, and morbidity risk linearly increased with temperature increase above $18.4^{\circ} \mathrm{C}$ in Hefei, China(Cheng et al., 2017). The delayed effects analysis results showed that temperature had lag effects for other subgroup except for people aged 41 years and over, The effects of temperature on BD appeared to be acute and greatest on the day of exposure(lag of 0 days), and female and people aged 0-6 years were sensitive to the effects of temperature on BD, and the results were consistent with the relevant studies (Li et al., 2016; WANG Jinyu1, 2018), which may be related to the relative weakness of gastrointestinal tract function for women and children aged 0-6 years. This finding was also in accordance with previous study(Liu et al., 2019). High temperature could increase the risk of bacillary dysentery. The main reasons for this may be the following two aspects, one of which is that the increase of temperature is beneficial to the survival and propagation of pathogens in the external environment(Qian Ying-jun, 2010). Meanwhile, the rise of temperature directly affects the whole process of food processing, transportation and storage, and increases the likelihood of people being infected with pathogens (Huang et al., 2012). Another mechanism is considered that bacillary dysentery is transmitted in the form of fecal-oral contact transmission, direct or indirect consumption of patients or carriers of fecal contaminants and infection, or indirect transmission of flies or cockroaches. Summer is just the best season for flies and cockroaches to survive, in addition, changes in the living habits and behavior of individuals in high temperature environments include eating habits and the frequency and range of outdoor activities et al (Ma et al., 2015a).

Meanwhile, the effects of PM2.5 and PM10 on the bacillary dysentery were also discussed, and it was found that both low and high concentrations of PM10 could significantly increase the risk of bacillary dysentery, and that low concentrations of PM2.5 could increase the risk of disease in a shorter lag time, suggesting that PM2.5 had an acute harm to the health of the population, and the sensitivity of women and people aged 0-6 to pollutants was higher than that of other groups. Previous studies have shown that air pollutants such as PM2.5, PM10 and $\mathrm{NO}_{2}$ were closely related to the increase in population morbidity and mortality, even at lower levels (Analitis et al., 2018). There was a study indicating that every year more than 13 million deaths worldwide were due to environmental pollutants, and approximately $24 \%$ of the diseases were caused by environmental exposures that might be averted through preventive measures (Hou et al., 2012). . Toxicological studies have revealed that PM2.5 was actually a carrier whose surface could adsorb a variety of substances that would cause a variety of symptoms and diseases, that is to say, what is the most harmful to the human body is not the particulate matter itself, but the chemical substances adsorbed on the particulate matter. Therefore, when the high concentration of PM2.5 is more conducive to the air bacillary dysentery pathogens attached to the $\mathrm{PM}_{2.5}$, outdoor activists will carry pathogenic bacteria attached to PM2.5 or PM10 and other absorption into the human respiratory system, circulatory system and digestive system et c, leading to the onset of bacillary dysentery(Yan-ping, 2013). In this study, we found that PM2.5 and PM10 also have delayed effects on BD, especially having significant effect on female, and children aged 0-6 years. A study found that Crohn disease was more 
commonly in young people, and there was a trend towards more Crohn disease with increasing PM exposure (OR=1.73, 95\% Cl: 0.98 3.03)(Gilaad G. Kaplan et al., 2010). Possibly because women and children have low immunity, they are more likely to cause intestinal damage when exposed to air pollutants, and since women are required to pick up and send their children to school and accompany their children to play outdoors, they are more exposed to the outdoors and are more likely to inhale more particulate matter. On the other hand, population exposed the air pollutants such as PM2.5 and PM10 had a certain impact on the body's immune mechanisms and metabolic capacity, and studies have found that exposure and air pollutants can alter the body's genes (Bind et al., 2014). When the human body is exposed to PM2.5 and PM10, it may alter the genotype of the body's response to the pathogen of bacillary dysentery, so the resistance to the body decreases when exposed to various pathogens. However, the results showed that PM10 has no significant single lag effect on bacterial dysentery on people aged 41 years and over. Related research also found adults aged 44-57 years were less likely to develop Crohn disease in region of higher concentration of $\mathrm{NO}_{2}$ and PM10. Differential effects observed across ages may have been due to exposure misclassification (Gilaad G. Kaplan et al., 2010). The results suggested that individuals should strengthen the defensive measures on the relevant influencing factors, for example, people go out with multiple masks, and so on, and the relevant government departments should also strengthen prevention and control measures, such as using sprinklers to properly cool the streets and reduce the concentration of inhaled particulate matter in the air in summer.

It should be acknowledged that there are some limitations in our study. One of the limitation is that the effects of many factors, such as social and economic status, health services, and environmental hygiene, could not be analyzed in our study. Moreover, due to lack of detailed laboratory information, we cannot identify the pathogens typing of bacillary dysentery in Lanzhou. Therefore, further studies with detailed laboratory information of bacillary dysentery pathogens, socioeconomic and other possible risk factors should be conducted to examine the association between the specific strains of bacillary dysentery and environmental factors in order to have a better understanding of the health impacts of environmental factors.

\section{Conclusions}

Temperature, PM2.5 and PM10 are closely related to the incidence of bacillary dysentery. Our findings suggest adaptation plans that target vulnerable populations in susceptible communities should be developed to reduce health risks.

\section{Abbreviations}

$B D$ : Bacillary dysentery

GAM: Generalized additive model

GCV: Generalized cross-validation value 
DLNM: Distributed lag non-linear model

$R R$ : Risk ratio

ARIMA: Auto-regressive integrated moving average

\section{Declarations}

\section{Ethics approval and consent to participate}

The study was approved by the Institute Review Board (IRB) of the School of Public Health, Lanzhou University. The study did not involve individual participants, and no individual patient information was collected. As aggregated data with no personal information were involved, this study was exempt from obtaining informed consent.

\section{Consent for publication}

Not applicable.

\section{Availability of data and material}

Apply to the availability of these data are not publicly available. A person who wants to access the raw data should contact with the corresponding author.

\section{Competing interests}

The authors declare that they have no competing interests.

\section{Funding}

This study was supported by Lanzhou Talent Innovation and Entrepreneurship Project (No.2017-RC-16), the Fundamental Research Funds for the Central Universities (No.Izujbky-2015-265) and the National Natural Science Foundation of China (No.81102205).

\section{Authors' contributions}

XWR and XLH conceived and designed the study to conception, study design, data analysis, and interpretation of data and wrote the manuscript. WZ, XDC, HPM and YCL contributed to the data analysis. $X Y Z, X K Z$ and SL contributed to the data collection. All authors read and approved the final manuscript.

\section{Acknowledgments}

We thank the Lanzhou Center for Disease Control and Prevention, China, for providing the data.

\section{References}


1. Analitis A, De' Donato F, Scortichini M, Lanki T, Basagana X, Ballester F, et al. Synergistic Effects of Ambient Temperature and Air Pollution on Health in Europe: Results from the PHASE Project. Int $\mathrm{J}$ Environ Res Public Health. 2018; 15(9): 1856-1867.

2. Bai L, Cirendunzhu, Woodward A, Dawa, Zhaxisangmu, Chen B, et al. Temperature, hospital admissions and emergency room visits in Lhasa, Tibet: a time-series analysis. Sci Total Environ. 2014; 490: 838-48.

3. Bind MA, Lepeule J, Zanobetti A, Gasparrini A, Baccarelli A, Coull BA, et al. Air pollution and genespecific methylation in the Normative Aging Study: association, effect modification, and mediation analysis. Epigenetics. 2014; 9: 448-458.

4. Bollati V, Baccarelli A. Environmental epigenetics. Heredity (Edinb). 2010; 105: 105-112.

5. Breitner S, Wolf K, Devlin RB, Diaz-Sanchez D, Peters A, Schneider A. Short-term effects of air temperature on mortality and effect modification by air pollution in three cities of Bavaria, Germany: a time-series analysis. Sci Total Environ. 2014; 485-486: 49-61.

6. CAO Ruoming CL, JIANG Chao, JING Yiming, ZHOU Lin, ZHANG Lin, LIU Shouqin. Association between ambient ozone and mortality of respiratory diseases in Jinan, China: a time-series analysis. Journal of Shandong University(Health Sciences). 2018; 56: 1-7.

7. Checkley W, Epstein LD, Gilman RH, Figueroa D, Cama RI, Patz JA, et al. Effects of El Niño and ambient temperature on hospital admissions for diarrhoeal diseases in Peruvian children. The Lancet. 2000; 355: 442-450.

8. CHEN Wei LY, CHEN Zheng-li, MA Gui-fang, GUO Xiao-fang, XUAN Shui-li, HE Jing-yang. Analysis on Relativity between epidemic characteristics of bacillary dysentery and Meteorological factors in Henan Province in 2010. Modern Preventive Medicine. 2012; 39: 5818-5820.

9. Cheng J, Xie MY, Zhao KF, Wu JJ, Xu ZW, Song J, et al. Impacts of ambient temperature on the burden of bacillary dysentery in urban and rural Hefei, China. Epidemiol Infect. 2017; 145: 1567-1576.

10. Gao L, Zhang Y, Ding G, Liu Q, Zhou M, Li X, et al. Meteorological variables and bacillary dysentery cases in Changsha City, China. Am J Trop Med Hyg. 2014;90: 697-704.

11. Gordon CJ. Role of environmental stress in the physiological response to chemical toxicants. Environmental Research. 2003; 92: 1-7.

12. Hou L, Zhang X, Wang D, Baccarelli A (2012) Environmental chemical exposures and human epigenetics. Int J Epidemiol 41: 79-105.

13. Huang C, Barnett AG, Wang X, Tong S. Effects of extreme temperatures on years of life lost for cardiovascular deaths: a time series study in Brisbane, Australia. Circ Cardiovasc Qual Outcomes. 2012; 5: 609-14.

14. Juan ZXH. Correlation analysis on gastrointestinal diseases and meteorological variables in Beijing. Journal of Changchun University of Chinese Medicine. 2015; 31: 105-109.

15. Kim J, Lim Y, Kim H. Outdoor temperature changes and emergency department visits for asthma in Seoul, Korea: A time-series study. Environ Res. 2014; 135: 15-20. 
16. Kaplan GG, Hubbard J, Korzenik J, et al. The inflammatory bowel diseases and ambient air pollution: a novel association. Am J Gastroenterol. 2010; 105:2412-2419.

17. Li K, Zhao K, Shi L, Wen L, Yang H, Cheng J, et al. Daily temperature change in relation to the risk of childhood bacillary dysentery among different age groups and sexes in a temperate city in China. Public Health. 2016; 131: 20-26.

18. LI Yang WD, ZHOU Ruyi. Relationship between air pollutant and respiratory diseases. Journal of environmental pollution and prevention. 2018; 40: 508-517.

19. Liu J, Wu X, Li C, Xu B, Hu L, Chen J, et al. Identification of weather variables sensitive to dysentery in disease-affected county of China. Sci Total Environ. 2017; 575: 956-962.

20. Liu Z, Liu Y, Zhang Y, Lao J, Zhang J, Wang H, et al. Effect of ambient temperature and its effect modifiers on bacillary dysentery in Jinan, China. Sci Total Environ. 2019; 650: 2980-2986.

21. Liu ZD, Li J, Zhang Y, Ding GY, Xu X, Gao L, et al. Distributed lag effects and vulnerable groups of floods on bacillary dysentery in Huaihua, China. Sci Rep. 2016; 6: 1-8.

22. LU Xiao-min CH-y, WU Dong-mei, SUN Zhongg-you. Influence of air pollutants on occurrence risk of hand-foot-mouth disease in Yancheng city. Chinese Journal of Woman and Child Health Research. 2018; 29: 276-280.

23. Ma W, Zeng W, Zhou M, Wang L, Rutherford S, Lin H, et al. The short-term effect of heat waves on mortality and its modifiers in China: an analysis from 66 communities. Environ Int. 2015; 75: 103109.

24. Ma Y, Zhang T, Liu L, Lv Q, Yin F. Spatio-Temporal Pattern and Socio-Economic Factors of Bacillary Dysentery at County Level in Sichuan Province, China. Sci Rep. 2015; 5: 1-9.

25. QIAN Ying-jun LS-z, WANG Qiang, YANG Kong, YANG Guo-jing, LV Shan, ZHOU Xiao-nong. Research progress on the impact of climate change on human health. ADVANCES IN CLIMATE CHANGE RESEARCH. 2010; 6: 241-247.

26. QIANG Li YJ-p, TAO Yan, LIU Ya-meng. Relationship between daily incidence of bacterial dysentery and meteorological factors in Chengguan District of Lanzhou City. J Environ Health.2013; 30: 644646.

27. Ren C, Williams GM, Tong S. Does particulate matter modify the association between temperature and cardiorespiratory diseases? Environ Health Perspect.2016; 114: 1690-16966.

28. Renate Stiller-Winkler, Helga Mel, I, Gahiele Leng CS, 2 and Reinhard Dolgner3. Influence of Air Pollution on Humoral Immune Response. J Clin Epidemiol Vol. 1996; 49: 527-534.

29. SUN peiyuan $₫$ ZHANG deshan Wy, ZHAO na,PU yonglan, GUO qing, SHI rujing, Llyang Relationship between incidence of bacillary dysentery and meteorological factors. Capit al Journal of Public Health. 2008; 2: 100-103.

30. Von Seidlein L, Kim DR, Ali M, Lee H, Wang X, Thiem VD, et al. A multicentre study of Shigella diarrhoea in six Asian countries: disease burden, clinical manifestations, and microbiology. PLoS Med. 2006; 3: 1559-1569. 
31. WANG Jin-yu, DONG Ji-yuan, LI Shou-yu, LI Pu, JIA Qing, WANG Ling-qing, CHANG Xu-hong. Distributed lag effects on the relationship between daily mean temperature and the incidence of bacillary dysentery in Lanzhou city. Journal of Peking University(Health Sciences). 2018; 1-13.

32. Xuan-yi Wang aFT, b Donglou Xiao,c Hyejon Lee,a Jacqueline Deen,a Jian Gong,d Yuliang Zhao,e, Weizhong Zhou fWL, g Bing Shen,h Yang Song,i Jianming Ma,j Zheng-mao Li,c Zijun Wang,c Pu-yu Su,b, Nayoon Chang aJ-hX, i Pei-ying Ouyang,k Lorenz von Seidlein,a Zhi-yi Xu,a \& John D Clemensa. Trend and disease burden of bacillary dysentery in China (1991-2000). Bulletin of the World Health Organization. 2006; 84: 561-568.

33. Li X, Wang N, Ding G, et al. The relationship between meteorological factors and the risk of bacillary dysentery in the highest incidence area of Hunan Province, China during 2005-2010: The relationship between meteorological factors and the risk of bacillary dysentery in the highest incidence area of Hunan Province, China during 2005. weather. 2018(Suppl 4).

34. Yan-ping SZ-hC. An Overview of PM2.5 Impacts on Human Health. Environmental Science and Technology. 2013; 26: 75-78.

35. YANG Jun OY-C, DING Yan, CHEN Ping-yan. Distributed lag non-linear model. Chinese Journal of Health Statistics. 2012; 29: 772-777.

36. Yu G, Li Y, Cai J, Yu D, Tang J, Zhai W, et al. Short-term effects of meteorological factors and air pollution on childhood hand-foot-mouth disease in Guilin, China. Sci Total Environ. 2019; 646: 460470.

37. Zhang Y, Bi P, Hiller JE, Sun Y, Ryan P. Climate variations and bacillary dysentery in northern and southern cities of China. J Infect.2007; 55: 194-200.

38. Zhang Y, Rohde C, Tierling S, Jurkowski TP, Bock C, Santacruz D, et al. DNA methylation analysis of chromosome 21 gene promoters at single base pair and single allele resolution. PLoS Genet. 2009; 5: $1-15$.

39. Zhou yanli $X w$, Zhang haiyan,Ma lixian,Pan jinghai,Huang hui,Liu qinghua. Time series analysis on bacillary dysentery andme teorological factors in Dongcheng distr ict, Beijing. $D$ isease Surveillance. 2009; 24: 697-700.

\section{Tables}

\section{Table 1}

Summary statistic for daily environment variable and daily number of BD cases from 2014 to 2017 in Lanzhou, China. 


\begin{tabular}{|c|c|c|c|c|c|c|}
\hline variables & $X \pm S D$ & $\min$ & $P_{25}$ & $P_{50}$ & $P_{75}$ & $\max$ \\
\hline $\begin{array}{l}\text { Cases of BD } \\
\text { Air pollutants variable }\end{array}$ & $4.84 \pm 4.19$ & 0.00 & 2.00 & 4.00 & 6.00 & 35.00 \\
\hline PM2.5/ $/ \mathrm{g} / \mathrm{m}^{3}$ ) & $53.44 \pm 27.01$ & 12.00 & 36.00 & 46.00 & 64.00 & 327.00 \\
\hline $\mathrm{PM} 10 /\left(\mu \mathrm{g} / \mathrm{m}^{3}\right)$ & $124.47 \pm 82.18$ & 23.00 & 82.00 & 108.00 & 145.00 & 1393.00 \\
\hline $\mathrm{CO} /\left(\mathrm{mg} / \mathrm{m}^{3}\right)$ & $1.35 \pm 0.72$ & 0.40 & 0.80 & 1.10 & 1.60 & 4.80 \\
\hline $\mathrm{NO}_{2} /\left(\mu \mathrm{g} / \mathrm{m}^{3}\right)$ & $51.44 \pm 21.44$ & 12.00 & 36.00 & 48.00 & 62.00 & 146.00 \\
\hline $\left.\mathrm{O}_{3_{-}} 8 \mathrm{~h} / \mu \mathrm{g} / \mathrm{m}^{3}\right)$ & $85.77 \pm 36.05$ & 8.00 & 58.00 & 80.00 & 109.00 & 194.00 \\
\hline \multicolumn{7}{|l|}{ Meteorological variable } \\
\hline Tem & $7.73 \pm 9.66$ & 6.70 & -0.90 & 8.90 & 16.20 & 26.40 \\
\hline Pressure & $.6 \pm 4.26$ & 797.40 & 308.60 & 311.30 & 814.60 & 825.10 \\
\hline Relative humidity/\% & $.51 \pm 16.23$ & 20.00 & 49.00 & 60.00 & 72.00 & 100.00 \\
\hline Wind speed/(m/s) & $1.95+0.50$ & 0.50 & 1.50 & 1.80 & 1.95 & 6.30 \\
\hline Sunshine durat & $7.07 \pm 3.92$ & 0.00 & 4.65 & 8.00 & 9.80 & 13.70 \\
\hline
\end{tabular}

Table 2

Relative risk (95\% confidence interval) of BD in different subgroups associated with 1 unit increase in daily mean temperature, with ref. at $9^{\circ} \mathrm{C}$.

\begin{tabular}{cccccc}
\hline \multirow{2}{*}{ Lag } & \multicolumn{5}{c}{ Relative risk (95\% confidence interval) } \\
\cline { 2 - 6 } (d) & male & female & 0-6years & $7-40 y e a r s$ & $\geq 41$ years \\
\hline 0 & $1.008(1.004,1.013)^{\mathrm{a}}$ & $1.010(1.003,1.017)^{\mathrm{a}}$ & $1.020(1.013,1.028)^{\mathrm{a}}$ & $1.010(1.002,1.019)^{\mathrm{a}}$ & $0.998(0.990,1.006)$ \\
3 & $1.006(1.002,1.010)^{\mathrm{a}}$ & $1.007(1.001,1.013)^{\mathrm{a}}$ & $1.017(1.011,1.023)^{\mathrm{a}}$ & $1.009(1.002,1.016)^{\mathrm{a}}$ & $0.996(0.989,1.002)$ \\
6 & $1.003(1.000,1.007)^{\mathrm{a}}$ & $1.004(0.999,1.009)$ & $1.013(1.007,1.018)^{\mathrm{a}}$ & $1.007(1.001,1.014)^{\mathrm{a}}$ & $0.994(0.988,1.000)$ \\
9 & $1.001(0.998,1.004)$ & $1.001(0.996,1.006)$ & $1.009(1.004,1.014)^{\mathrm{a}}$ & $1.005(0.999,1.012)$ & $0.991(0.986,0.998)^{\mathrm{a}}$ \\
11 & $0.999(0.996,1.003)$ & $0.999(0.994,1.004)$ & $1.006(1.001,1.012)^{\mathrm{a}}$ & $1.004(0.998,1.011)$ & $0.990(0.984,0.997)^{\mathrm{a}}$ \\
14 & $0.997(0.993,1.001)$ & $0.996(0.990,1.002)$ & $1.002(0.996,1.009)$ & $1.003(0.995,1.010)$ & $0.988(0.981,0.995)^{\mathrm{a}}$ \\
\hline
\end{tabular}

${ }^{\mathrm{a}}$ Confidence intervals that do not overlap the null value of $\mathrm{RR}=1$.

\section{Table 3}

Relative risk (95\% confidence interval) of BD in different subgroups associated with 5 unit increase in daily mean PM2.5, with ref. at $50 \mu \mathrm{g} / \mathrm{m}^{3}$.

\begin{tabular}{cccccc}
\hline \multirow{2}{*}{ Lag } & \multicolumn{5}{c}{ Relative risk (95\% confidence interval) } \\
\cline { 2 - 6 } (d) & male & female & 0-6years & 7-40years & $\geq 41$ years \\
\hline 0 & $1.011(1.005,1.016)^{\mathrm{a}}$ & $1.014(1.008,1.020)^{\mathrm{a}}$ & $1.021(1.014,1.027)^{\mathrm{a}}$ & $1.001(0.994,1.008)$ & $1.013(1.006,1.020)^{\mathrm{a}}$ \\
3 & $1.007(1.003,1.012)^{\mathrm{a}}$ & $1.013(1.008,1.018)^{\mathrm{a}}$ & $1.016(1.010,1.022)^{\mathrm{a}}$ & $1.002(0.996,1.007)$ & $1.011(1.005,1.016)^{\mathrm{a}}$ \\
6 & $1.004(1.000,1.008)^{\mathrm{a}}$ & $1.012(1.007,1.016)^{\mathrm{a}}$ & $1.012(1.007,1.017)^{\mathrm{a}}$ & $1.003(0.997,1.007)$ & $1.008(1.003,1.013)^{\mathrm{a}}$ \\
9 & $1.001(0.997,1.004)$ & $1.011(1.006,1.015)^{\mathrm{a}}$ & $1.007(1.002,1.012)^{\mathrm{a}}$ & $1.004(0.998,1.008)$ & $1.006(1.001,1.011)^{\mathrm{a}}$ \\
11 & $0.998(0.994,1.002)$ & $1.010(1.005,1.015)^{\mathrm{a}}$ & $1.004(0.999,1.010)$ & $1.004(0.998,1.009)$ & $1.004(0.998,1.009)$ \\
14 & $0.995(0.990,1.000)$ & $1.009(1.003,1.014)^{\mathrm{a}}$ & $0.999(0.993,1.006)$ & $1.005(0.998,1.011)$ & $1.001(0.995,1.007)$ \\
\hline
\end{tabular}


${ }^{a}$ Confidence intervals that do not overlap the null value of $R R=1$.

\section{Table 4}

Relative risk (95\% confidence interval) of BD in different subgroups associated with 10 unit increase in daily mean PM10, with ref. at $110 \mu \mathrm{g} / \mathrm{m}^{3}$.

\begin{tabular}{cccccc}
\hline \multirow{2}{*}{ Lag } & \multicolumn{5}{c}{ Relative risk (95\% confidence interval) } \\
\cline { 2 - 6 } (d) & male & female & 0-6years & 7-40years & $\geq 41$ years \\
\hline 0 & $0.991(0.988,0.995)$ & $0.997(0.993,0.999)^{\mathrm{a}}$ & $0.990(0.986,0.994)^{\mathrm{a}}$ & $1.001(0.996,1.003)$ & $0.994(0.991,0.998)^{\mathrm{a}}$ \\
3 & $0.994(0.991,0.996)$ & $0.996(0.993,0.999)^{\mathrm{a}}$ & $0.991(0.988,0.995)^{\mathrm{a}}$ & $0.999(0.996,1.002)$ & $0.995(0.993,0.999)^{\mathrm{a}}$ \\
6 & $0.996(0.994,0.998)$ & $0.995(0.993,0.998)^{\mathrm{a}}$ & $0.993(0.990,0.996)^{\mathrm{a}}$ & $0.998(0.995,1.001)$ & $0.997(0.995,1.000)$ \\
9 & $0.999(0.997,1.001)$ & $0.995(0.992,0.998)^{\mathrm{a}}$ & $0.994(0.992,0.997)^{\mathrm{a}}$ & $0.998(0.995,1.001)$ & $0.999(0.997,1.002)$ \\
11 & $1.001(0.998,1.003)$ & $0.994(0.992,0.997)^{\mathrm{a}}$ & $0.995(0.993,0.998)^{\mathrm{a}}$ & $0.998(0.995,1.001)$ & $1.000(0.998,1.003)$ \\
14 & $1.003(1.001,1.006)^{\mathrm{a}}$ & $0.994(0.991,0.997)^{\mathrm{a}}$ & $0.997(0.994,1.001)$ & $0.997(0.994,1.002)$ & $1.001(0.999,1.005)$ \\
\hline
\end{tabular}

${ }^{\mathrm{a}}$ Confidence intervals that do not overlap the null value of $\mathrm{RR}=1$.

\section{Figures}






Fig. 1 The location of Lanzhou, Gansu Province in China

\section{Figure 1}

[See figure] Note: The designations employed and the presentation of the material on this map do not imply the expression of any opinion whatsoever on the part of Research Square concerning the legal status of any country, territory, city or area or of its authorities, or concerning the delimitation of its frontiers or boundaries. This map has been provided by the authors. 

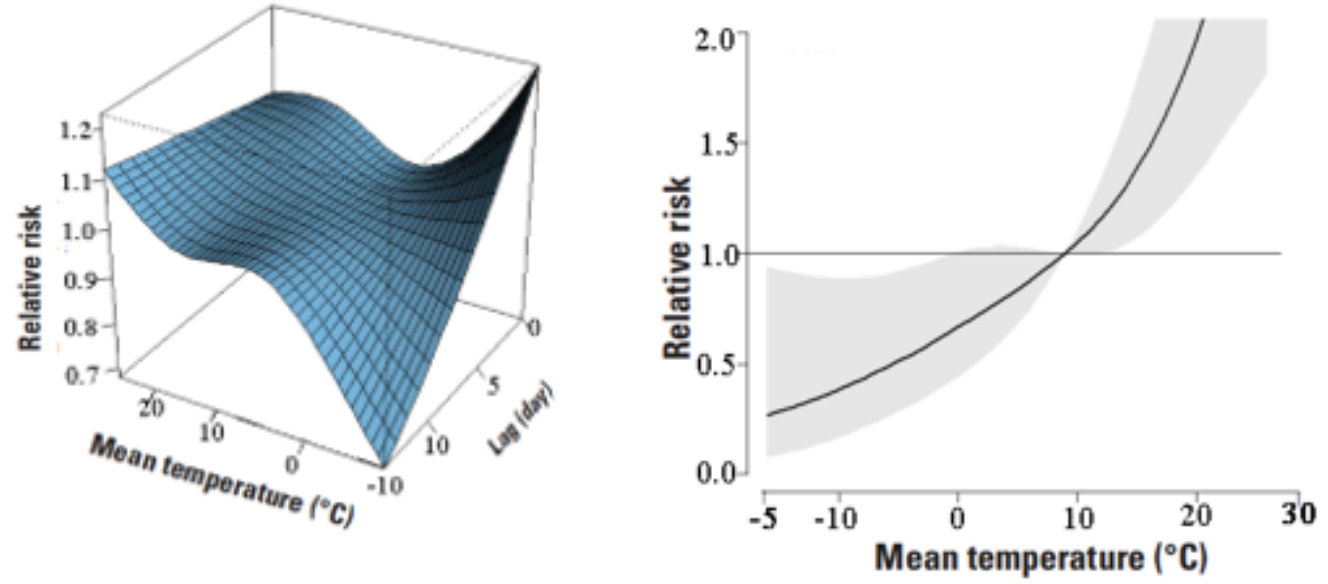

Figure 2

3D \& Overall plot of RR along temperature and lags, with ref. at $9^{\circ} \mathrm{C}$. (a) A 3D image of the relative risk (RR) of $\mathrm{BD}$ along the mean temperature (here $9^{\circ} \mathrm{C}$ ) and lags. Here the legends respectively (from the left) are: relatively risk (RR), daily temperature and lag periods. (b) The estimated overall effect of mean temperature $\left({ }^{\circ} \mathrm{C}\right)$ over 14 days on daily cases of bacillary dysentery. (here $9^{\circ} \mathrm{C}$ ).
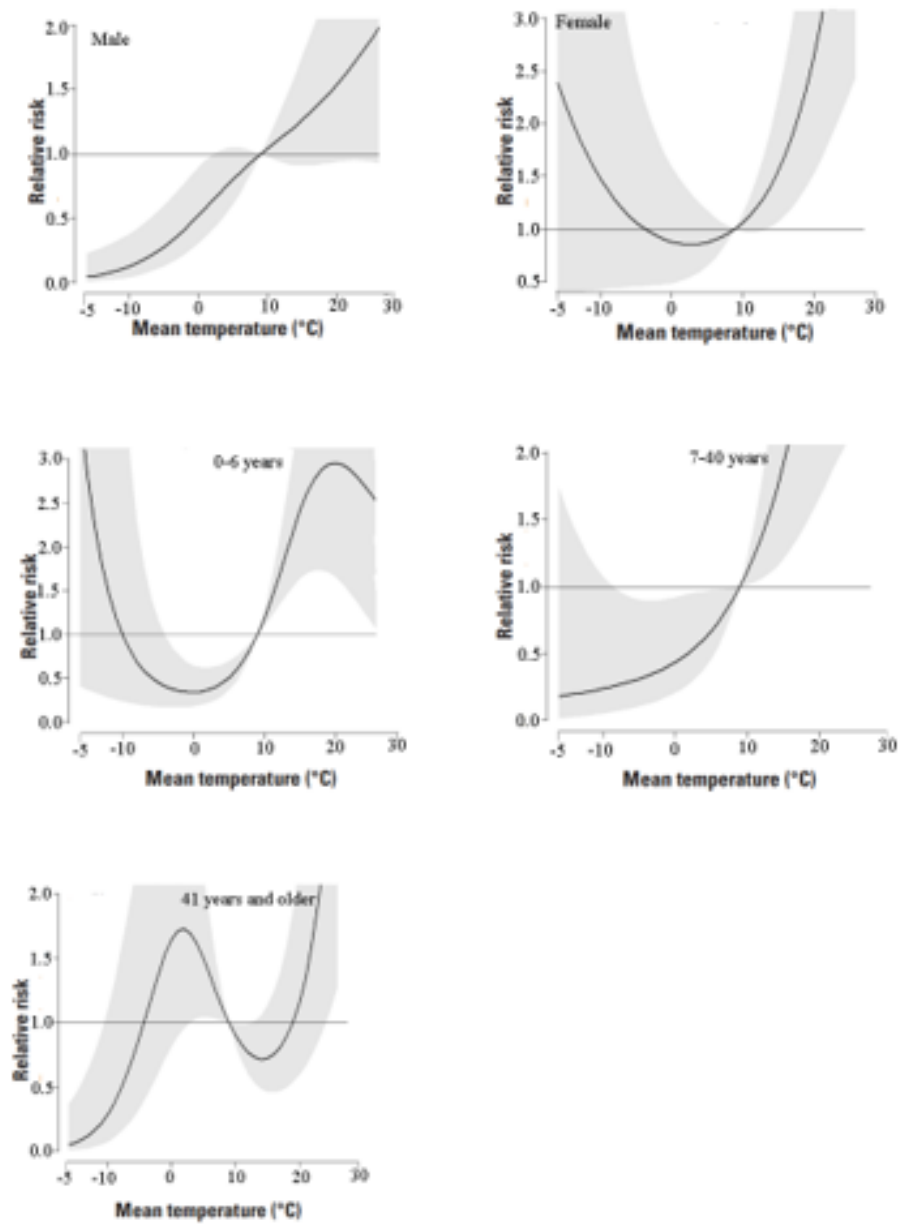


\section{Figure 3}

The overall effects of daily mean temperature on BD among different sex and age groups. RR (relative risk), Grey area ( $95 \%$ confidence intervals of overall effects of daily mean temperature).
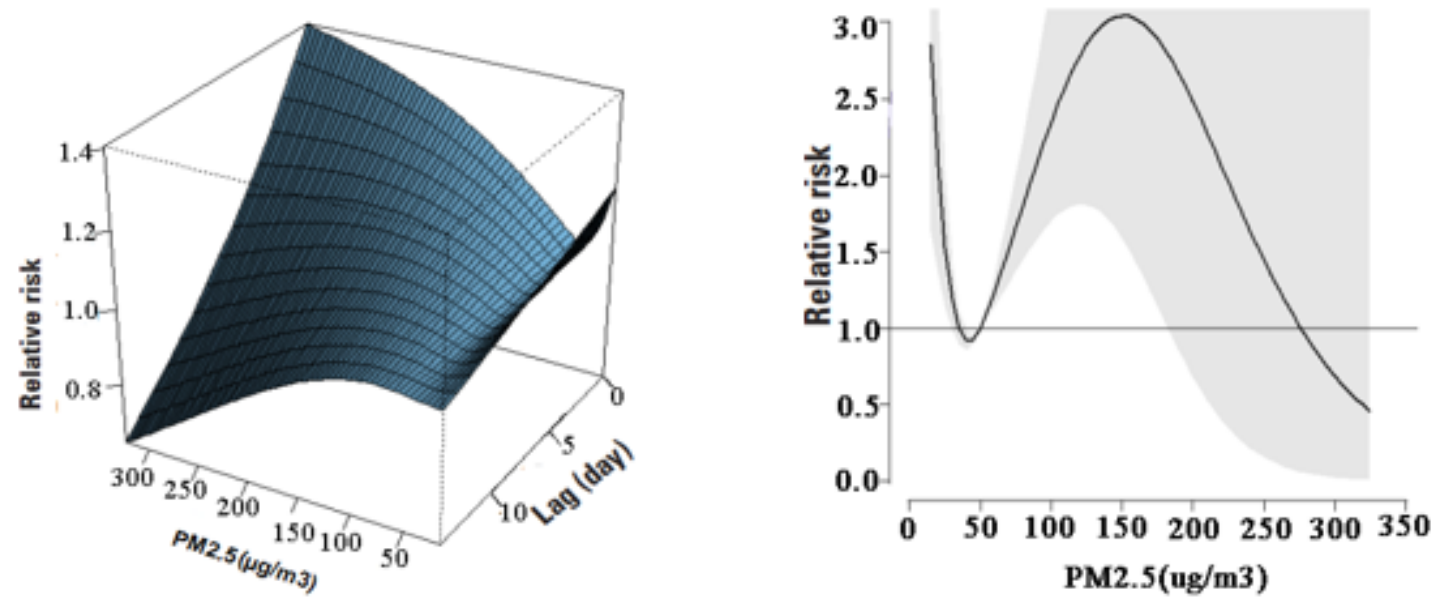

\section{Figure 4}

3D \& Overall plot of RR along PM2.5 and lags, with ref. At 50 $\mathrm{g} / \mathrm{m} 3$. (a) A 3D image of the relative risk (RR) of BD along the mean PM2.5 (here $50 \mu \mathrm{g} / \mathrm{m} 3$ ) and lags. Here the legends respectively (from the left) are: relatively risk (RR), daily PM2.5 and lag periods. (b) The estimated overall effect of mean PM2.5 concentration $(\mu \mathrm{g} / \mathrm{m} 3)$ over 14 days on daily cases of bacillary dysentery. 

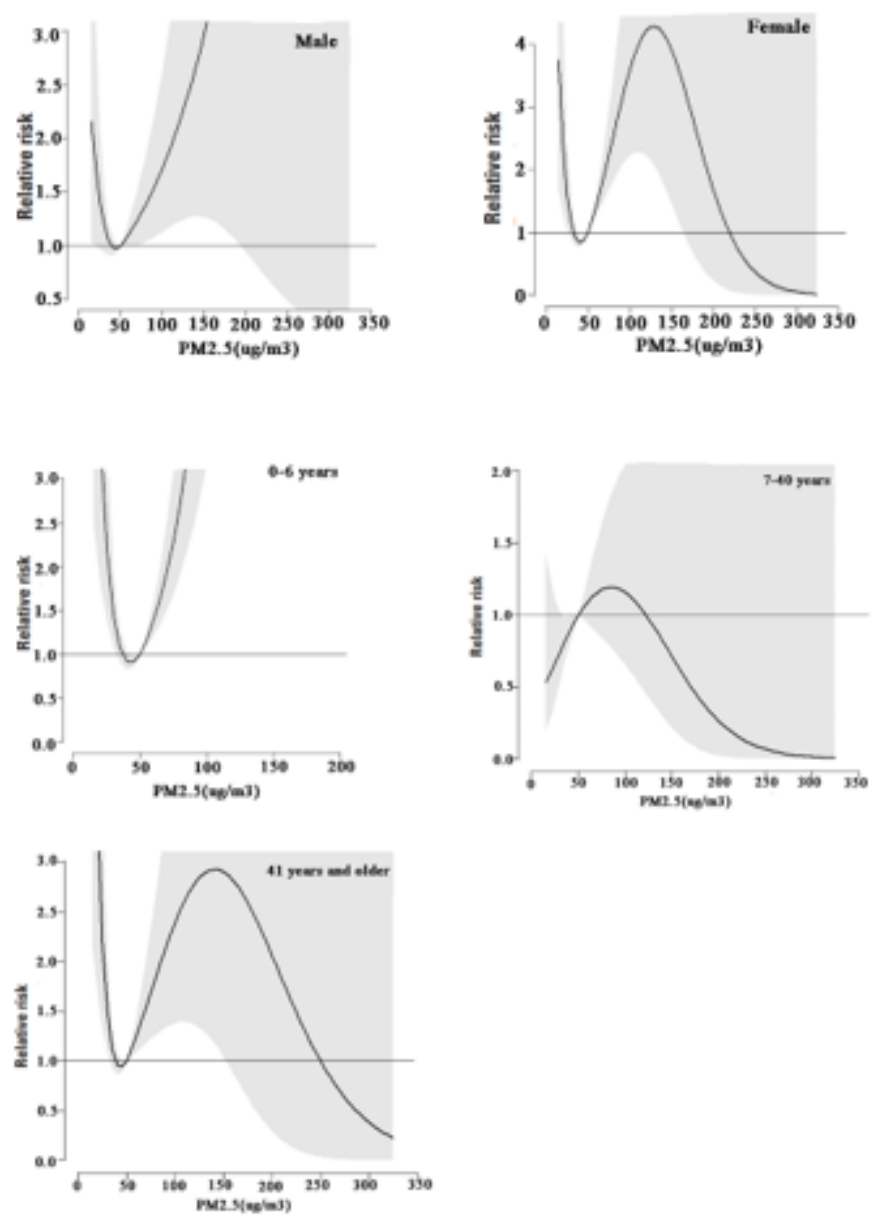

Figure 5

The overall effects of daily mean PM2.5 on BD among different sex and age groups. RR (relative risk), Grey area (95\% confidence intervals of overall effects of daily mean PM2.5).
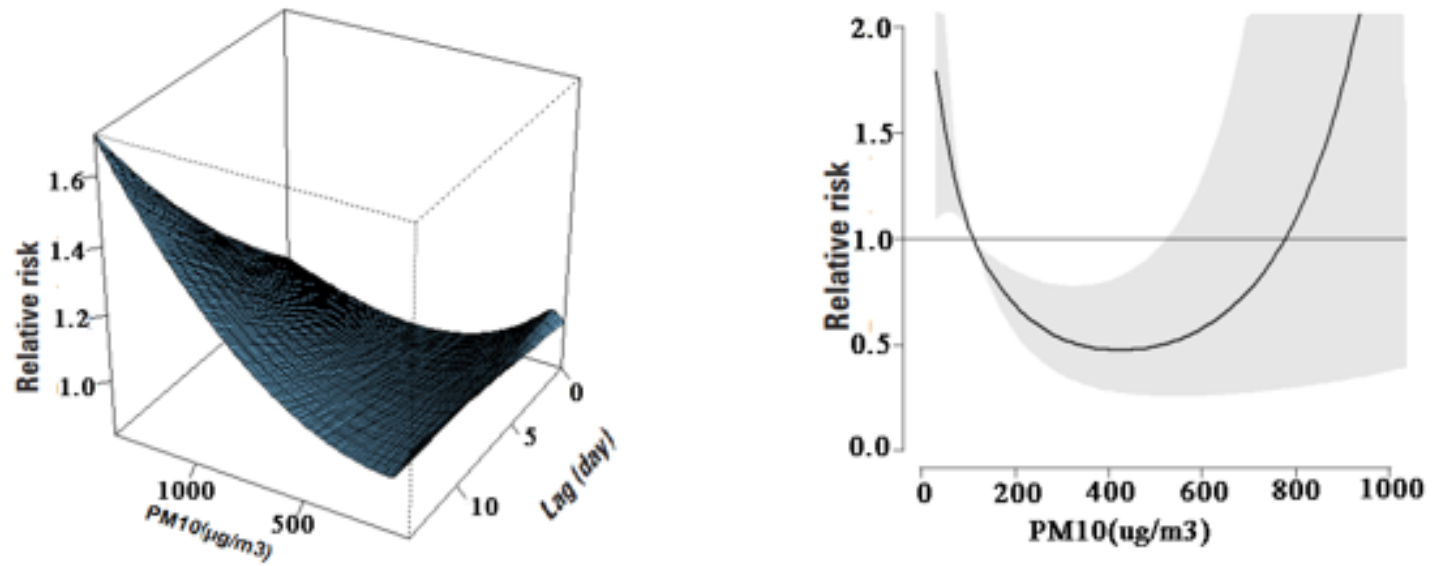

Figure 6

3D \& Overall effect plot of RR along PM10 and lags, with ref. At 110 $\mu \mathrm{g} / \mathrm{m3}$. (a) A 3D image of the relative risk (RR) of BD along the mean PM10 (here $110 \mu \mathrm{g} / \mathrm{m} 3$ ) and lags. Here the legends respectively (from the 
left) are: relatively risk (RR), daily PM10and lag periods. (b) The estimated overall effect of mean PM10 concentration $(\mu \mathrm{g} / \mathrm{m} 3)$ over 14 days on daily cases of bacillary dysentery
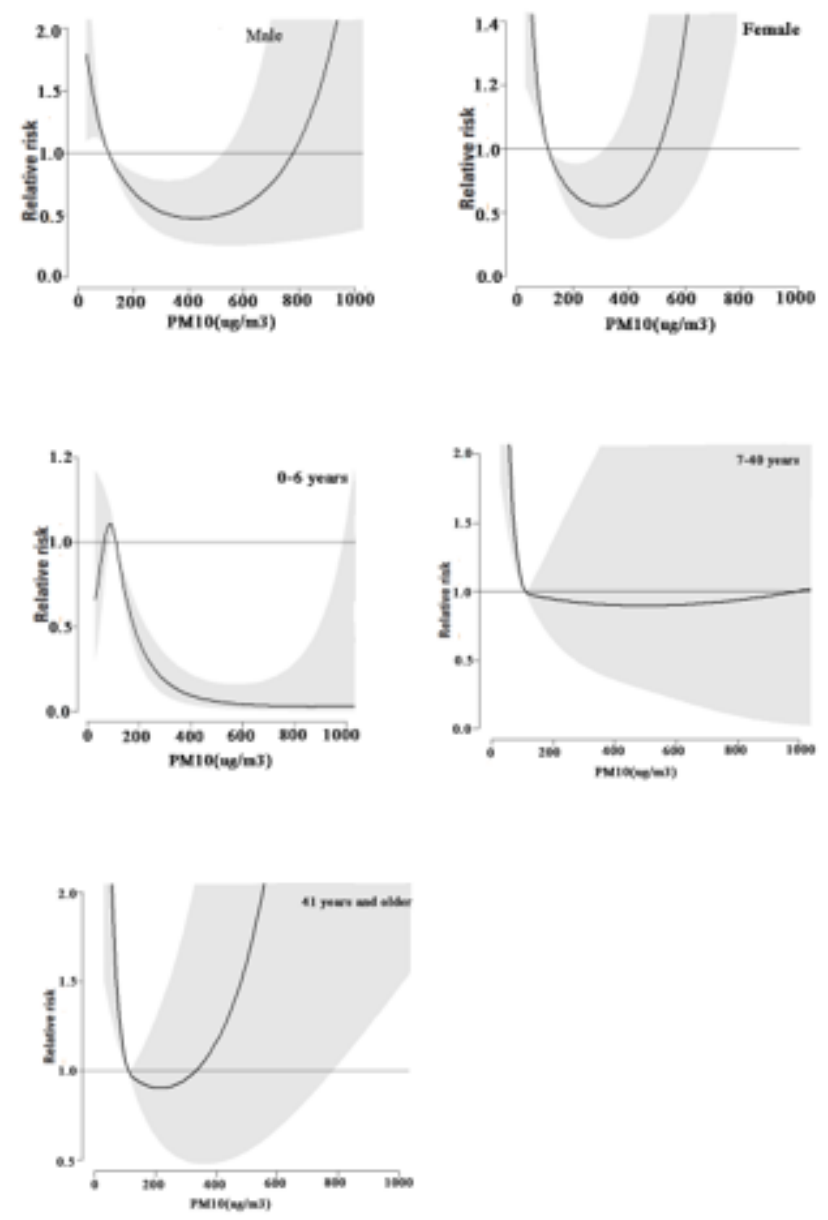

\section{Figure 7}

The overall effects of daily mean PM10 on BD among different sex and age groups. RR (relative risk), Grey area (95\% confidence intervals of overall effects of daily mean PM10). 